COMMENT: This study adds one more negative report regardingthe Feingold Diet theory. The National Institutes of Health Consensus Development Panel on "Defined Diets in Childhood Hyperactivity" (1982) concluded that the Feingold diet may be helpful for a small number of children with hyperkinesis but these decreases in hyperactivity were not observed consistently.

The interest in the Feingold hypothesis, although waning in the US, is flourishing in England where consciousness about ecology and pure foods is growing.

\title{
HEADACHE
}

SELF-HYPNOSIS CONTROL OF MIGRAINE

In a prospective study at the Minneapolis Children's Medical Center 28 children with classic migraine were treated with propranolol ( $3 \mathrm{mg} / \mathrm{kg} / \mathrm{d}$ ) or placebo for 3 months, using a cross over design, followed by an equal period of self-hypnosis. The mean number of headaches per child during placebo and propranolol periods were similar (13.3 and 14.9 respectively) and was significantly reduced (5.8) with self-hypnosis $(\mathrm{P}=.045)$, a standard progressive relaxation exercise. (Olness K, Macdonald JT, Uden DL. Pediatrics 1987; 79:593597)

COMMENT: Non-pharmacological methods (biofeedback, self-hypnosis, dietary) of treatment of juvenile migraine are displacing the previously popular pharmacologic options eg propranolol and phenytoin. Phenytoin prophylactic treatment is attended by potential adverse toxicity and propranolol in controlled studies has been found ineffective (Forsythe WI et al. Develop Med Child Neurol $1984 ; 26: 737-741)$. At the Hospital for Sick Children, Great Ormond Street, London, an oligoantigenic dietary regime is preferred (Wilson J, Brett E. personal communication and Lancet 1983; ii:86)

\section{INFECTIONS OF THE NERVOUS SYSTEM}

SUBACUTE SCLEROSING PANENCEPHALITIS (SSPE)

In England and Wales, unlike the United States, SSPE is a persisting problem. The number of new notifications of SSPE in a 6 year period $(1980-86)$ was 60 (10 cases per year). There were 62 deaths from SSPE in the same period! Immunisation against measles increased from 50 to 688 between 1980 and 1986. Of those children who developed SSPE, less than $5 \%$ had been immunised (Drs Miller and Barnes, personal communications). Intraventricular Interferon, an arduous and poorly tolerated therapy, is under investigation, but prevention by the wider application of measles immunisation is the most obvious solution to this generally fatal disorder. Having seen 6 cases of SSPE in the past 6 months, I can attest to the distress to child, family, nurses, social workers and physicians involved. 